of glioma retinae it is regretable that radium has been allocated to the treatment of inoperable cases and for the alleviation of pain and that no mention has been made of the work on the treatment of glioma retinae in the second eye which was begun in England by Foster Moore and has been carried on successfully.

The book contains chapters on the ophthalmoscope and its uses in the examination of the eye; and on the visual fields, perimetry and scotometry. A special chapter has been allotted to the retinal circulation, and others deal with diseases of the retina, choroid, vitreous body and injuries of these structures.

This book should prove of considerable value to ophthalmologists, internists and neurologists. It is admirably written. The type, paper, illustrations and binding are well produced.

\title{
OBITUARY
}

\section{WILLIAM LANG}

It is with regret that we report the death of Mr. William Lang, on July 13, at the age of 84 . He had been in fair health, although feeble, and it was during a stay at Crowborough that he developed a chill that caused his death in a few days. Born in Exeter on December 28, 1852, he was the son of Isaac Lang. He was educated at the Moravian School in Lausanne and acquired a good working knowledge of French and German. In 1870 he entered the London Hospital, at the age of 18, and qualified as M.R.C.S. in 1874. He became F.R.C.S. in 1879. He served as House Physician and House Surgeon, and later on was demonstrator of physiology and anatomy in the Medical College. Here he met J. E. Adams, and so was directed to ophthalmology. He became Assistant Surgeon to the Central London Ophthalmic Hospital in 1879, Ophthalmic Surgeon to the Middlesex Hospital in 1880, and followed Adams at Moorfields in 1884, to whose practice he also succeeded. He was one of the 113 founders of the Ophthalmological Society, and his death leaves only three original members, Sir Thomas Barlow, Sir George Berry and Sir Lindo Ferguson. He was senior Vice-President in 1903 and acted as President owing to the death, during office, of Dr. David Little. In 1916 he acted as President of the Ophthalmological Section of the Royal Society of Medicine.

He married first Susan, daughter of the late W. T. Buckland, of Auckland, New Zealand, and lived for a time at Wood Green, but 


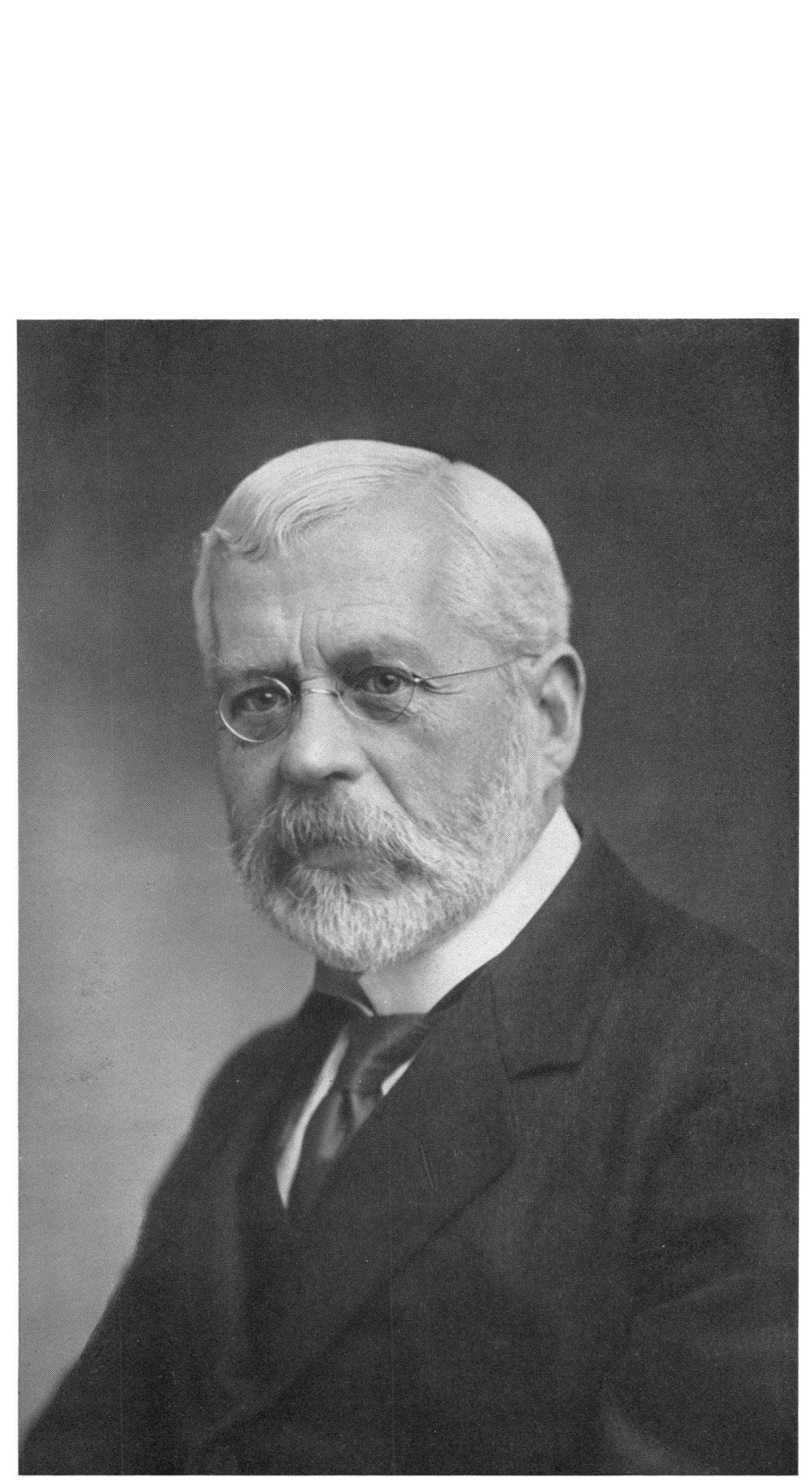

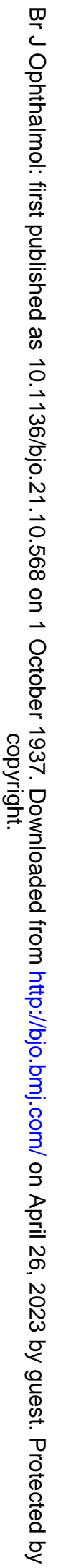


moved in 1885 to Chiswick. By this marriage there were a son and daughter. The son, Basil Thorn, followed his father in ophthalmology and was a man of exceptional ability and originality. He became a member of the staff at Moorfields in 1923 and died in 1928 at the age of 47 after a short illness. Secondly, he married Isabella Jane, widow of A. M. Dunlop, who died in 1927.

Whilst a resident in Chiswick, he was a neighbour of William Morris, and he made a collection of the books published by the Kelmscott Press. In 1892 he removed to 22, Cavendish Square, which was to remain his home until within a short time of his death when he removed to 35, Cavendish Square.

Lang was not a prolific writer. Both writing and public speaking he found difficult, and he went through agonies of mind if he had to make a speech or take part in a public function. Nevertheless, his output was considerable, and his more important publications were of great value. From 1881, when he became one of the founders of the Ophthalmological Society, until 1906 the records show that he often brought cases forward and joined in discussions. In 1882 he published, with W. A. Fitz-Gerald, a paper on the movements of the eyelids in association with the movements of the eyes. This was his first paper of note and in it the action of the inferior rectus muscle in the downward movement of the lower lid is proved. Sir William Gowers had previously stated that the lower lid was depressed by the pressure of the limbus upon the margin of the lower lid. After the paper had been written the authors discovered that Bonnet and Richet had described the action of the inferior rectus muscle 40 years previously. In 1886 he was a member of the Committee which reported on 211 cases of sympathetic ophthalmitis. In 1887 he published his account of the insertion of an artificial globe into Tenon's capsule after excising the eye. This operation had been independently suggested by Adams Frost in the previous year. In 1888 he described the condition of the ciliary processes and suspensory ligament of the lens after removal of the iris. In this case the iris had been torn away by an accident, and the eye was otherwise normal. Lang was unable to see any result from the application of atropine or eserine in the eye, although the eserine produced a characteristic pain in the eye. In 1889 he offered an explanation of enophthalmos following a blow upon the eye, which retained full visual acuity, by suggesting that the orbital sac had become herniated into the antrum of Highmore. In 1892 he showed a case of chancre of the semilunar fold of conjunctiva which was followed by interstitial keratitis in the affected eye. In 1895 appeared his only book "The Methodical Examination of the Eye." It was put out as Part I of a guide to the practice of ophthalmology for students and practitioners. At various times in later life he made efforts to write further volumes which were to 
include one on operative surgery. For this some photographs were taken of him operating.

In 1895 he also took part in the discussion on the operative treatment of myopia by removal of the crystalline lens. He pointed out the tendency to detachment of the retina following the removal of senile cataract in myopic patients. It was the experience he gained in needling the lens in high myopia and the subsequent removal of the softened lens matter that led him to devise the incision in the upper part of the cornea midway between the limbus and the centre of the cornea, so as to avoid prolapse of iris and also permit the detachment of any capsular synechia which might follow and for which he devised his well known twin knives in 1889.

He was the first to prove that the iridescent crystals seen in a senile cataract were typical cholesterin crystals.

Lang was for many years the editor of the Royal London Ophthalmic Hospital Reports, and he contributed several important papers in collaboration with Sir James Barrett, who was then living in London. The first was in 1886 on "The Refractive Condition of the Eyes of Mammalia." A great variety of animals were examined, 185 eyes in all, and the majority were hypermetropic. In the same year appeared a long and elaborate paper on the action of miotics on the accornmodation. This was a continuation of Donders' work published in 1864 . In 1887 they published a paper that had considerable practical importance, as it is upon the information contained in it that the use of cycloplegics in refraction work is built. This paper was "The Action of Myotics and Mydriatics on the Accommodation." It is the record of a patient and careful investigation, and in it was introduced an enquiry into the action of a mixture of homatropine and cocaine (often known as Lang's drops), and of the extremely ingenious oily solution of these alkaloids. It was also shown in this paper how easily and safely the action of these drugs can be controlled by the subsequent use of eserine. The last paragraph in the paper announces "After paralysis of the sphincter pupillae and ciliary muscle has been effected by the application of homatropine or of homatropine and cocaine, the application of eserine causes a constriction of the pupil, and an approximation of the near point to such an extent that in the great majority of cases the individual can, in a few minutes, resume work of all kinds without inconvenience."

In 1888 appeared two papers on convergent concomitant strabismus in which were considered the results of treatment of convergent strabismus by the correction of the refraction error with and without tenotomy : the possibility of alteration of vision in the squinting eye: familial tendency to strabismus: age of onset and 
alleged causes: whether amblyopia is the cause of strabismus, and the influence of atropine on concomitant convergent strabismus.

In 1889 Lang published, with Casey A. Wood, an examination of the patellar tendon reflex in sixty-two cases of interstitial keratitis. It was absent in 10 per cent. and "decidedly abnormal" in 30 per cent.

Lang had always the practical side of ophthalmology in view, and here he was a master. He improved many of the instruments in common use. The McHardy perimeter, until it was superseded by better models, was improved by him in many ways. The speculum with solid blades is still in common use, and his twin knives for dividing anterior synechiae mark an epoch in the improvement in cataract extraction, as by them he drew attention to the importance of avoiding the inclusion of lens capsule in the wound. It took many years for this sound teaching to sink in, but nowadays, everywhere, whether cataract be extracted in the capsule or extracapsularly, great pains are taken to avoid that annoying and sometimes dangerous complication.

Another matter that will always be associated with Lang's name is the importance of focal sepsis in inflammatory diseases of the eye, and the elimination of focal sepsis as far as possible before operations on the eye are undertaken. Lang's attention was drawn to the consideration of oral sepsis by Mr. William Hern. Mr. Hern had noted the frequent co-existence of oral sepsis and rosacea, and Lang had been one of the earliest to note the connection between keratitis and rosacea. From this hint Lang began to preach the danger of oral sepsis and although others carried the matter to extremes, few will deny how important is focal sepsis in connection with eye disease.

As a clinical observer and all round ophthalmologist, Lang was unsurpassed in his day. His operating and his resource in difficult cases will always be remembered by those who had the good fortune to be his house surgeons. He had a peculiar nervous tremor of the hands that was always present, but it in no way, at any rate until he became old, interfered with his operative skill. He had about $6 \mathrm{D}$. of myopia and when he operated always put his spectacles on his forehead by lifting them with his little finger, and then, with his own eyes near to the eye upon which he was operating, seemed to see everything, much of which had escaped the notice of others.

As a clinical teacher he will always be remembered. All his students were "dear boys," and with them he was extremely popular. His more serious pupils who were to be ophthalmic surgeons owe very much to him. How characteristic was his examination of a patient at the out-patient desk, with spectacles on forehead, noticing a lesion missed by many, which he was often pleased to designateBrobdingnagian. 
He was extremely patient and courteous to everyone, and his most cherished expletive, which he saved for moments of greatest provocation was-" Dash my wig."

When he resigned his appointment at the Middlesex Hospital his many old students gave him a complimentary dinner at which the late Sir Henry Morris presided.

Lang lived 25 years after he had retired from active hospital work; he did not, therefore, come into contact with the younger generation of ophthalmic surgeons, and his great services to ophthalmology are apt to be overlooked. Those of us who worked with him and remember him, often have his name upon our lips when we meet one another, and we will always remember that dapper little man, always good tempered, always courteous, always full of sound advice, especially in difficult cases: and when we all foregather in the Elysian fields there will be one pleasure that we will wish-to see him again perform a glaucoma iridectomy.

Mr. Lang was devotedly cared for by his daughter in his later years, and to her, the sole survivor of the family, we offer our sympathy and at the same time express to her our thanks and admiration for all her goodness to him.

\section{NOTES}

International DURING the period of the XV Concilium Organization against Ophthalmologicum to be held in Cairo from Trachoma December 8 to 14,1937 , there will be sessions of The International Organization against Trachoma.

On Thursday, December 9, there will be a meeting of the present Executive Committee; this will be followed by a plenary meeting of the Delegates from the National Ophthalmological Societies together with the subscribing Members of The International Organization against Trachoma.

The names of such Delegates should be notified to the President of The International Organization against Trachoma at 33, Welbeck Street, London, W.1, thirty days before the opening of the Congress. Notices to this effect have already been addressed to each Society.

The programme of the scientific sessions is as follows:-

(1) Introductory Address by the President, Mr. MacCallan.

(2) The Microbiological Aetiology of Trachoma;

Reporters-Dr. Phillips Thygeson (U.S.A.), Professor Dr. Grüter (Germany), Professor Dr. Oguchi (Japan), Drs. Cuénod and Nataf (Tunisia), Dr. Rötth (Hungary), Dr. Poleff (Morocco). 